\title{
Cool Farm Tool - Potato: Model Description and Performance of Four Production Systems
}

\author{
A. J. Haverkort • J. G. Hillier
}

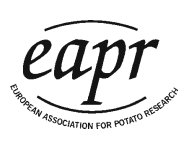

Received: 31 August 2011 / Accepted: 27 October $2011 /$

Published online: 22 December 2011

(C) The Author(s) 2011. This article is published with open access at Springerlink.com

\begin{abstract}
The Cool Farm Tool - Potato (CFT-Potato) is a spreadsheet programme that allows the calculation of the amount of $\mathrm{CO}_{2}$ equivalents that it costs to produce $1 \mathrm{t}$ of potato. The spreadsheet was adapted from an original generic version of the tool, and completed for potato production in diverse production areas in the world applying different levels of technology. The $\mathrm{CO}_{2}$ embedded in chemicals during their production and released from the soil after nitrogen fertilization in the CFTPotato has been updated to consider more recent products and production methods. Energy costs of the operations in the original version taken from generic data provided by the American Society of Agricultural and Biological Engineers Standard, however, were altered (usually increased) where there was evidence from practical sources that the original figures did not apply. For example, the figure of around 161 of diesel per ha for potato harvesting in the original version was corrected to 601 of diesel per ha based on observational data. Figures for typical potato operations such as windrowing were supplied. Irrigation with pumps powered by diesel or electricity from the grid, with a centre pivot, a rain gun, drip irrigation and flooding and energy cost for extracting water from deeper sources were also added. We added data for grading, washing, store loading and unloading, the application of a sprout suppressant and storage with ventilation of ambient air or
\end{abstract}

\section{A. J. Haverkort ( $\square)$}

Plant Research International, Wageningen University and Research Centre, P.O. Box 616, 6700 AP Wageningen, The Netherlands

e-mail: anton.haverkort@wur.nl

\section{J. G. Hillier}

Institute of Biological and Environmental Sciences, School of Biological Sciences, University of Aberdeen, 23 St. Machar Drive, Aberdeen AB24 3UU, UK e-mail: j.hillier@abdn.ac.uk

\section{A. J. Haverkort}

Department of Plant Production and Soil Science, University of Pretoria, Pretoria, Republic of South Africa 
forced refrigeration. The CFT-Potato can be used by growers to calculate the actual costs of $1 \mathrm{t}$ of potato in terms of kilograms $\mathrm{CO}_{2}$ and explore the repercussion of altered management options. Here the comparison of four potato production systems in the Netherlands is shown: seed potatoes $\left(115 \mathrm{~kg} \mathrm{CO}_{2} / \mathrm{t}\right)$, table potatoes $(77 \mathrm{~kg}$ $\left.\mathrm{CO}_{2} / \mathrm{t}\right)$, starch potatoes $(71 \mathrm{~kg} \mathrm{CO} / \mathrm{t})$ and organic potato $\left(82 \mathrm{~kg} \mathrm{CO}_{2} / \mathrm{t}\right)$. Based on potato dry matter, however, starch potato has the lowest footprint mainly due to the extensive use of pig slurry of which the production and transport $\mathrm{CO}_{2}$ costs are attributed to the pig production chain.

Keywords Carbon dioxide emissions $\cdot \mathrm{Cool}$ Farm Tool $\cdot$ Irrigation · Organic potato Seed potato $\cdot$ Starch potato $\cdot$ Storage $\cdot$ Table potato

\section{Introduction}

Potato production uses energy: embedded in the seed potatoes, in the chemical fertilizers and crop protection chemicals and in the tractor operations such as tillage, planting, spraying, spreading and harvesting. In addition, electricity may be used for irrigation, grading, store (un)loading and storage. All these factors involve the release of the greenhouse gas $(\mathrm{GHG})$ carbon dioxide in factories producing the chemicals, farm implements, transport and power plants. Nitrous oxides are released from the soil, particularly where there is excess not used by plants, and especially under wet conditions (e.g., Oenema et al. 2005). Recently the food industry shows an increased interest in the amount of carbon dioxide that is emitted per unit of produce leaving the processing plant, and some studies have emerged in recent years quantifying emissions from agriculture and farming operations (e.g., Lal 2004; Hillier et al. 2009). Walker Crisps in the UK displays on the front of its package of $50 \mathrm{~g}$ that its production costs $120 \mathrm{~g}$ of $\mathrm{CO}_{2}$. On the reverse it announces: "We promise to continue working with the Carbon Trust and our suppliers to further reduce the carbon footprint of our crisps". Hillier et al. $(2011 \mathrm{a}, \mathrm{b})$ developed a tool that can be used by growers to calculate the amount of $\mathrm{CO}_{2}$ equivalents it costs to yield a product on 1 ha. It is intended as a decision support tool for growers to calculate the current $\mathrm{CO}_{2}$ footprint and to explore management options with altered applications of chemicals and field operations. The development of the Cool Farm Tool was mostly performed under the commission from Unilever Sustainable Agriculture with input from the Sustainable Food Lab via the Cool Farming Options project (http://sustainablefoodlab.org/projects/climate). The model has several sub-models breaking down the overall emissions by greenhouse gas emitted and farm management aspects:

- GHG emissions from the production and distribution of a range of fertilizer types were taken from the Ecoinvent database (Ecoinvent 2007).

- Nitrous oxide $\left(\mathrm{N}_{2} \mathrm{O}\right)$ emissions related to fertilizer application were estimated using the multivariate empirical model of Bouwman et al. (2002) which takes fertilizer type, rate, climate and soil characteristics into consideration. Although relatively small quantities of $\mathrm{N}$ are released from soil as nitrous oxide [around $1 \%$ of $\mathrm{N}$ applied according to IPCC Tier 1 (IPCC 2006)], it is important to the GHG budget as it is 298 times more damaging than $\mathrm{CO}_{2}$ over a 100-year horizon (IPCC 2006). 
- $\mathrm{NO}$ and $\mathrm{NH}_{3}$ based on the model of FAO/IFA (2001) and converted to $\mathrm{N}_{2} \mathrm{O}$ via the factor 0.01 as given in IPCC (2006). Leaching is assumed to occur at a rate of $0.3 \times \mathrm{N}$ applied for moist climate zones only-and the conversion factor to $\mathrm{N}_{2} \mathrm{O}$ of 0.01 is also employed.

- Emissions of $\mathrm{CO}_{2}$ from soil resulting from urea application or liming are also accounted for using the IPCC emissions factors (IPCC 2006) of 0.20 and 0.12 , respectively.

- $\mathrm{CO}_{2}$ emissions from (or accumulations in) soils depend on climate, soil characteristics and tillage practises and crop residue management such as burning straw on the one hand or incorporating green manure on the other, based on Ogle et al. (2005).

- The effects of manure and compost addition on soil $\mathrm{C}$ stocks are derived from the data of Smith et al. (1997): about $0.04 \%$ change of soil organic matter concentration per tonne dry matter of manure or compost.

- Averaging data from Audsley for agrochemicals (fungicides, growth regulator, herbicides and insecticide), the tool uses the figure of $20.5 \mathrm{~kg} \mathrm{CO}_{2}$ equivalent per product application per ha.

- Direct energy usage (petrol, diesel, electricity) on the farm for field operations (ploughing - harvest) and primary processing were taken from ASABE technical standards (ASABE 2006a, b)

- Country-specific grid electricity emissions were taken from the GHG protocol's "Emission Factors for Cross-Sector Tools" (GHG protocol 2003). Hydro-, wind or solar renewable electricity sources are also included using Ecoinvent figures.

- The following conversion factors are employed: 11 of diesel contains 38.6 MJ, $1 \mathrm{hp}=0.75 \mathrm{~kW}, 1 \mathrm{kWh}=0.92 \mathrm{~kg} \mathrm{CO}$, and produces $3.11 \mathrm{~kg} \mathrm{CO}(\mathrm{GHG}$ protocol 2003). The original tool allows for different emissions factors to be used if known (for biodiesel for example).

The Cool Farm Tool Version 1.0 has been engineered in Microsoft Excel and is available for free at http://www.growingforthefuture.com/content/Cool+Farm+Tool.

The Cool Farm Tool is a Microsoft Excel spreadsheet with "Usage, license and disclaimer" on the first sheet, "Crop management" on the second, "Field energy use" on sheet 3, "Cooling and storage" on the next followed by "Results and graphs". Subsequent sheets contain default factors, sub-models and data.

Table 1 shows the type of information a grower has to supply to the tool in order to calculate the amount of $\mathrm{CO}_{2}$ (equivalents) per hectare. The soil structure has repercussions for the amount of energy that is needed to work the soil and the other soil characteristics such as moisture, $\mathrm{pH}$ and organic matter concentration and climate influence $\mathrm{N}_{2} \mathrm{O}$ emission from the soil. The number of applications of pesticides includes all sprays of individual chemicals which can be more than one per spraying operation as is the case with a tank mix. Pre-emergence and pre-harvest (haulm killing) herbicides are included in this figure.

The authors conclude that in many cases, it is more important to consider emission per unit of product than per area of land. The Cool Farm Tool might be applied in combination with crop productivity and farm economic models, or perhaps in the future integrated in a single package. This would allow direct investigation into management policies to reduce GHG emissions which do not have a detrimental impact on productivity and profitability. 
Table 1 Information gathered per field in the CFT version 1 (animal production and operations related to cereal production-e.g., baling-not included)

\begin{tabular}{ll}
\hline Item & Options for completion by growers \\
\hline Climate & Temperate, tropical \\
Soil texture & Fine, medium, course \\
Soil organic matter (\%) & $<1.72,1.72-5.16,5.16-10.32,>10.36$ \\
Soil moisture & Moist, dry \\
Drainage & Poor, good \\
pH & $<5.5,5.5-7.3,7.3-8.5,>8.5$ \\
Amounts of N, P, K and Ca & Many formulations and compounds, broadcast \\
& or incorporated, solid or soluble, with or \\
& without emission inhibitor \\
Organic amendments & Compost, various slurries and manures \\
Number of applications of pesticides & \# \\
Fuel type & Diesel, petrol \\
Ploughing & Mouldboard, chisel, sub-soiling \\
Harrowing & Rollers, tine harrowing, cultivator \\
Ridging & \\
De-stoning & Lifting and hauling, windrowing \\
Planting & \\
Spreading & \\
Spraying & \\
Harvesting & Fertilizer, manure \\
\hline & \\
& \\
\hline
\end{tabular}

Objectives of the research we carried out and is presented here were to make the Cool Farm Tool applicable to potato and to illustrate its use by comparing four different potato production systems in the Netherlands: the production of seed potatoes, ware potatoes, starch potatoes and organic potatoes.

\section{Materials and Methods}

Development of the Cool Farm Tool - Potato

The Cool Farm Tool - Potato was based on a development version of the Cool Farm Tool 2.0. Noteworthy additions to the Cool Farm Tool 1.0 in this development version were:

1. Inclusion of more recent fertilizer databases (Fertilizers Europe, personal communication, 2010; based on Brentrup and Palliere 2008; part of the production values are reviewed and approved for future publication in the ELCD database, http://lca.jrc.ec.europa.eu/lcainfohub/datasetArea.vm). The new database contains European average fertilizer production emissions for 2006 and also for 2010 approximately (representing the best available fertilizer technology today). 
2. Modelling the use of slow-release (polymer coated) fertilizers and nitrification inhibitors (which slow the conversion of ammonia into nitrate) according to the meta-analysis of Akiyama et al. (2010). It is important to note that Akiyama et al. established significant impact of nitrification inhibitors for arable crops, but none for polymer-coated fertilizers.

To make the Cool Farm Tool potato specific, we first removed all entries that are not related to potato production such as cereal and animal-related operations. The tool was then adapted to allow estimation of emissions from the seed material all the way up to storage of the harvested product. The harvested product is not necessarily the marketed product as some markets require certain minimum size or want the tubers washed. The CFT-Potato calculates the $\mathrm{CO}_{2}$ print based on the marketed (finished product) yield.

Below, we cover key additions or refinements to the tool which were made to ensure the relevance to potato production. These additions concern:

1. Seed production and seed treatment;

2. Nematicides;

3. Slurry application;

4. Irrigation;

5. Haulm killing;

6. On-farm transportation;

7. Grading, store loading/unloading and storage, and

8. Sprout suppression.

\section{Seed Production and Seed Treatment}

Seed tubers when planted were assumed to have the same $\mathrm{CO}_{2}$ charge as the potatoes planted in the particular field since, although seed potato production is associated with lower yields than ware potato production, seed crops are also supplied with less fertilizer and water. The seed rate (in tonnes per hectare) was converted into $\mathrm{CO}_{2}$ (kilograms per hectare) and added to the $\mathrm{CO}_{2}$ footprint of the field before dividing it by the yield as to obtain the amount of $\mathrm{CO}_{2}$ produced per tonne of potato. For large distances of seed transport, its charge is also added as it can be substantial when transporting it by road, water or rail from northern latitudes or mountains over large distances. Next, chemical seed treatment was added as seed tubers are often treated with fungicides and or insecticides. We assumed rates of a few kilograms per amount of seed planted per hectare, so $20.5 \mathrm{~kg} \mathrm{CO}_{2}$ per individual chemical in the seed treatment (mixture). Seed potato growers usually add 5-7 1 of mineral oil per ha in the tank when spraying. This may add up to 601 of mineral oil over the whole season. We assumed each individual tank mix contribution of mineral oil to be equivalent to a chemical treatment also responsible for $20.5 \mathrm{~kg} \mathrm{CO}$.

\section{Nematicides}

Next we introduced the soil treatments against nematodes with nematicides such as Aldicarp and Temik and with emissions per unit active ingredient assumed to be 
$20.5 \mathrm{~kg} \mathrm{CO}_{2}$ as for other pesticides, but with a (user adjustable) default active ingredient concentration of $15 \%$.

Subsequently a number of operations specific to potato were added that were not mentioned in the original generic version of the tool, for which the energy costs which were taken from data gathered from potato growers and contracting companies in Argentina, South Africa, New Zealand, India (notably flood and drip irrigation) and the Netherlands. Where differences between observations were small, only few data were gathered and averaged (e.g., for the various irrigation methods), where they varied much (e.g., fuel costs of harvesting) as many as possible observations from farmers were gathered before calculating an average of fuel costs.

\section{Slurry Application}

Slurries in some countries such as the Netherlands have to be injected into the soil by heavy equipment. This operation needs approximately 2.5 times more diesel per hectare (average of three growers who supplied data from their contractor) than spreading and was added to the tool. We also inserted a slot for transport of slurries, manures and compost from the place where it is produced to the farm. In the Netherlands this can be as far as $170 \mathrm{~km}$ (round trip of $340 \mathrm{~km}$ ).

\section{Irrigation}

The application of water (irrigation) needs pumps that are fuelled by electricity or diesel. We asked growers how many millimetres of water they applied, every millimetre of water per hectare representing $10 \mathrm{~m}^{3}$ of water. Table 2 shows the energy content of this amount per millimetre. For each $10 \mathrm{~m}$ depth of the borehole, $0.95 \mathrm{kWh}$ was added and also $1 \mathrm{~km}$ horizontal pipe transport equating to around 1 additional bar, and $0.95 \mathrm{kWh}$ (average taken from three growers who stated that for $1 \mathrm{~km}$ horizontal transport, they have to increase pump pressure to $1 \mathrm{bar}$ in order to maintain pressure at the nozzle). Although individual fields are only irrigated with either electric or diesel pumps, to compare potatoes from different origins, it is significant to know which proportion of all potatoes sourced from an area is irrigated with which kind of pumps.

\section{Haulm Killing}

For mechanically top killing the foliage, we estimate 1.51 of diesel per ha and for haulm pulling $2.5 \mathrm{l}$. Growers of organic potato do not use any chemicals but may have to burn the foliage with propane or diesel burners (at a rate of around 2001 of propane per ha) when there is late blight present. So haulm killing has four entries: chemical, flailing, pulling and burning. For burning the amount of propane or diesel needs to be filled in.

\section{On-Farm Transportation}

Where fields are relatively far from the farm house, store and gate, the on-farm transport may represent a significant proportion of all energy used to produce 
Table 2 Energy use (in kilowatt-hour) per millimetre water; applied to a potato crop using surface water, for each $10 \mathrm{~m}$ depth for pumping $0.95 \mathrm{kWh}$ has to be added

\begin{tabular}{lcc}
\hline Irrigation method & Electricity & Diesel \\
\hline Centre pivot & 3.0 & 3.2 \\
Rain gun, sprinkler & 3.5 & 3.7 \\
Flooding & 1.6 & 1.7 \\
Drip irrigation & 2.0 & 2.1 \\
\hline
\end{tabular}

potatoes on 1 ha. The tool on the sheet "Field energy use" automatically inserts the amounts of seed, fertilizers, compost, manure and harvest potatoes from the previous sheet "Crop management", and the grower inserts the distance of the field(s) to the farm whereupon the tool calculates the $\mathrm{CO}_{2}$ footprint. Similarly the grower notes how many kilometres supervision to inspect the fields were dedicated in a light vehicle (per hectare). If a processor or trader is interested in the $\mathrm{CO}_{2}$ cost involved in the transport of the tubers to the factory or market, the tool allows making this calculation.

\section{Grading, Store Loading/Unloading, Storage}

The tubers that are harvested may receive some processing before being stored or delivered. The CFT-Potato has energy use inserted for washing and grading. For a particular field, all potatoes are usually either delivered to the market ( $0 \%$ stored) or all stored $(100 \%$ stored). For all potatoes of a farm or those delivered to a factory, however, only a certain proportion will be delivered immediately after harvest but most of them (e.g., 75\%) are stored for between e.g., 1 and 10 months. The grower fills in the percentage stored and the average storage period (e.g., 5.5 months). Before potatoes are stored, they have to be loaded (store loading or piling) which costs $0.017 \mathrm{kWh}$ per t. Assuming that store unloading takes as much energy, the tool uses a value of $0.034 \mathrm{kWh}$ per $\mathrm{t}$ for both actions together. Storage has up to five components:

- If potatoes enter the store wet, they need to be dried through ventilation equivalent to 1 month of ordinary ventilation $(4.00 \mathrm{kWh} / \mathrm{t} / \mathrm{month})$.

- If potatoes enter the store warm and need to be cooled down through ventilation, its energy requirements are $0.40 \mathrm{kWh} / \mathrm{t} /{ }^{\circ} \mathrm{C}$ cooling.

- Ventilation of the pile with ambient air to reduce $\mathrm{CO}_{2}$ concentration in the store and to cool the pile when the outside temperature is lower than inside. The energy costs of ventilation only are established at $4.00 \mathrm{kWh} / \mathrm{t} / \mathrm{month}$ between store loading until store unloading.

- Where ambient air is warmer, forced mechanical cooling (refrigeration) is needed which adds to the energy need: $1.11 \mathrm{kWh}$ per ${ }^{\circ} \mathrm{C}$ cooling per $\mathrm{t}$ per month. The grower or purchaser fills in the average temperature difference outside and inside the store during the storage period.

- In areas with cold winters, potatoes have to be heated before handling. Temperatures need to be increased from cold storage temperature (say 4 or $8^{\circ} \mathrm{C}$ ) to about $17^{\circ} \mathrm{C}$ to avoid low temperature bruising at handling at store unloading and transport. This is at a cost of 0.51 propane per t potatoes per ${ }^{\circ} \mathrm{C}$ heating.

In starch potato production in the Netherlands, potatoes are stored in a heap in a corner of the field covered by straw to protect it from freezing. Therefore the straw 
needs to be baled, transported and blown by machine to cover the heap. This is calculated at 0.04251 of diesel per $t$.

\section{Sprout Suppression}

Next, the energy costs of sprouting suppression with CIPC or ethylene application was calculated which for CIPC consists of the following components:

- $\quad$ Embedded energy 0.0321 of diesel equivalent per g active ingredient, typically a treatment may consist of $30 \mathrm{~g} \mathrm{t}^{-1}\left(2.237 \mathrm{~kg} \mathrm{CO}_{2} \mathrm{t}^{-1}\right)$

- Fogging 0.0261 of diesel per t per treatment $\left(0.061 \mathrm{~kg} \mathrm{CO}_{2} \mathrm{t}^{-1}\right)$

- Fanning 0.029 $\mathrm{kWh} \mathrm{t}^{-1}$ per treatment $\left(0.027 \mathrm{~kg} \mathrm{CO}_{2} \mathrm{t}^{-1}\right)$

Alternatively a grower may suppress sprouting by applying ethylene at a concentration of $10 \mathrm{ppm}$. This is at a rate of 0.031 ethylene per t per month. The energy costs and $\mathrm{CO}_{2}$ charge of ethylene application still have to be calculated and added to the Cool Farm Tool - Potato version. Table 3 summarizes the potato specific additions as well as additions that are of a generic nature such as irrigation.

\section{Data Collection for Four Cases in the Netherlands}

During spring 2011 two representative growers (regarding farm size, soil type, degree of mechanization and personal involvement in day to day operations) of table, organic, starch and seed potatoes were interviewed while completing the CFT-Potato (effectively Tables 1 and 3) on a computer. The growers know so well what and how much they apply and carry out that none of them needed to consult their papers, so completion usually took less than an hour. The data of the two growers were averaged so when one grower used $2.5 \mathrm{t}$ of seed and his colleague 2.7, the tool was filled in with 2.6. When one grower prepared the land with a subsoiler whereas the other used a moldboard plough, we completed the CFT by filling in 0.5 for each operation.

Some growers such as the starch potato growers in the northeast of the country and organic potato growers use a green manure fodder radish (Raphanus sativus subsp. oleiferus) that is ploughed under in spring and releasing nitrogen. Depending on the length of the stems $(20,40$ or $60 \mathrm{~cm})$, the amount of nitrogen it contains may be 30 , 61 or $91 \mathrm{~kg}$ per ha of which 15, 30 or $45 \mathrm{~kg}$ is available for crop growth (NMI 2011). The original CFT contains a routine for incorporating green manure. Some studies are still needed before it is decided which method will figure in the final version.

\section{Results}

Table 4 shows the values of inputs per system. The most striking differences between them are summarized as:

- Organic production uses neither synthetic fertilizers nor biocides. The low yields are mainly attributed to early harvest required by law when more than $1 \%$ of the foliage is infected with late blight caused by Phytophthora infestans. This is to avoid disease pressure on the neighbouring fields. 
Table 3 Potato specific items added (some have generic value, e.g. irrigation and slurry injection)

Item Options by moving to next item or scrolling

Product

Yield

Seed rate

Seed transport from seed grower to farm

Seed treatments

Soil treatment $\left(\mathrm{kg} \mathrm{ha}^{-1}\right)$

Foliar mineral oil treatment

Slurry injection

Irrigation, $\mathrm{mm}$

Mechanical haulm killing

On-farm transport $(\mathrm{km})$

Slurry, manure, compost transport producer to farm

Optional transport to market or processing factory

Washing

Grading

Store loading and unloading

Storage preparation

Storage

Sprout suppressant

Heating of tubers prior to unloading
Potato

Total yield (harvested product), marketable product after grading and or washing

Heavy weight road transport, rail, ship

Aldicarp, fosthiazate or similar, $10 \%$ or $20 \%$ active ingredient

Centre pivot, rain gun, drip or flooding, $\%$ of pumps driven by diesel or electricity, metres lifted, metres transported horizontally

Flailing, pulling, burning (propane or diesel)

Seed, fertilizers, potatoes, manure, slurry or compost, supervision

Light or heavy road transport, rail, ship

Percentage washed, diesel or electricity from the grid Percentage graded, diesel or electricity from the grid

Percentage loaded (also applies to storage and sprout control); heating before unloading

Cooling, yes/no number of degrees cooled; drying of wet potatoes, yes/no

Number of weeks, average temperature in pile and ambient (outside store), wet or dry tubers loaded

Dose and number of applications CIPC, use of ethylene Yes/no, number of degrees heating

- Table potato yields in the central marine clay polders are high $\left(65 \mathrm{t} \mathrm{ha}^{-1}\right)$, almost double that of organic and seed crops, both of them usually harvested well before crop maturity.

- The low yields of the starch crop - usually grown on sandy and peat soils with low water holding capacity - are inflated somewhat due to the high dry matter concentration of $24 \%$ (thus producing $10.6 \mathrm{t} \mathrm{ha}^{-1}$ dry matter) whereas table potato has a dry matter concentration of $19 \%\left(12.4 \mathrm{t} \mathrm{ha}^{-1}\right.$ dry matter).

- Seed rates are highest $\left(5.5 \mathrm{t} \mathrm{ha}^{-1}\right)$ in seed production aiming for small sized tubers when planting at a dense rate.

- Soil organic matter is highest in the starch production region. Here slurry use is highest $\left(26 \mathrm{t} \mathrm{ha}^{-1}\right)$ and makes the use of mineral phosphorus redundant. 
Table 4 Mean input values of the four potato production systems for the CFT-Potato

\begin{tabular}{|c|c|c|c|c|}
\hline Input & NL & NL & $\mathrm{NL}$ & NL \\
\hline Potato product & Table & Organic & Seed & Starch \\
\hline Harvested product $\left(\mathrm{t} \mathrm{ha}^{-1}\right)$ & 65 & 35 & 37.5 & 44 \\
\hline Marketed product $\left(\mathrm{t} \mathrm{ha}^{-1}\right)$ & 61 & 32 & 37.5 & 44 \\
\hline Seed rate $\left(\mathrm{t} \mathrm{ha}^{-1}\right)$ & 3.5 & 3.0 & 5.5 & 2.25 \\
\hline \multicolumn{5}{|l|}{ Seed transport } \\
\hline Variety & Milva & Various & Various & Various \\
\hline Soil texture & Medium & Medium & Medium & Coarse \\
\hline Soil organic matter $(\%)$ & 2 & 2 & $<1.7$ & 6 \\
\hline $\mathrm{pH}$ & 7 & 7 & 7 & $<5.5$ \\
\hline Mineral $\mathrm{N}\left(\mathrm{kg} \mathrm{ha}^{-1}\right)$ & 190 & 0 & 127.5 & 75 \\
\hline Mineral $\mathrm{P}_{2} \mathrm{O}_{5}\left(\mathrm{~kg} \mathrm{ha}^{-1}\right)$ & 52 & 0 & 100 & 0 \\
\hline Mineral $\mathrm{K}_{2} \mathrm{O}\left(\mathrm{kg} \mathrm{ha}^{-1}\right)$ & 115 & 0 & 265 & 50 \\
\hline Sheep manure $\left(\mathrm{t} \mathrm{ha}^{-1}\right)$ & 0 & 7.5 & 0 & 0 \\
\hline Poultry manure $\left(\mathrm{t} \mathrm{ha}^{-1}\right)$ & 7 & 0 & 0 & 0 \\
\hline Compost $\left(\mathrm{t} \mathrm{ha}^{-1}\right)$ & 0 & 5 & 0 & 0 \\
\hline Pig slurry (t ha $\left.{ }^{-1}\right)$ & 0 & 16 & 3 & 26 \\
\hline Green manure $\left(\mathrm{t} \mathrm{ha}^{-1}\right)$ & 0 & 0 & 0 & 20 \\
\hline Seed treatments & 1 & 0 & 2 & 2 \\
\hline Soil treatment $\left(\mathrm{kg} \mathrm{ha}^{-1}\right)$ & 0 & 0 & 2 & 3.5 \\
\hline Foliar mineral oil & 0 & 0 & 8 & 0 \\
\hline Chemical treatments & 14 & 0 & 29 & 18 \\
\hline Sub-soiling & 0.5 & 0 & 0 & 0.5 \\
\hline Mouldboard ploughing & 0.5 & 1 & 1 & 0.5 \\
\hline Ridging & 1 & 2 & 1 & 2 \\
\hline Harrowing & 1 & 1 & 1 & 1 \\
\hline Planting & 1 & 1 & 1 & 1 \\
\hline Tine harrowing & 0 & 0 & 0 & 1 \\
\hline Manure spreading & 0.5 & 2 & 0.2 & 2.5 \\
\hline Slurry injection & 0 & 0 & 0 & 1 \\
\hline Pesticide spraying & 14 & 0 & 9.5 & 17 \\
\hline Fertilizer spreading & 3 & 0 & 2 & 2 \\
\hline $\mathrm{mm}$ water irrigated by gun & 40 & 40 & 0 & 12 \\
\hline Haulm flailing & 1 & 1 & 1 & 1 \\
\hline Haulm burning & 0 & 0.7 & 0 & 0 \\
\hline Harvesting + hauling to store & 1 & 1 & 1 & 1 \\
\hline $\mathrm{km}$ on farm transport & 1 & 5 & 2 & 4 \\
\hline Fertilizer on farm transport & 1,021 & 0 & 1,418 & 314 \\
\hline Organic amendments (OA) & 7 & 25 & 3 & 25 \\
\hline Transport OA $\mathrm{km}$ to farm & 110 & 100 & 100 & 130 \\
\hline Grading electric & 1 & 0 & 1 & 0 \\
\hline Stored $(\%)$ & 100 & 100 & 70 & 33 \\
\hline
\end{tabular}


Table 4 (continued)

\begin{tabular}{|c|c|c|c|c|}
\hline Input & NL & NL & NL & NL \\
\hline Loading/unloading & 1 & 1 & 1 & 1 \\
\hline Months stored & 6 & 6 & 8 & 4 \\
\hline Degree $<$ ambient in store & 0 & -3 & -2 & 0 \\
\hline CIPC $30 \mathrm{~g} / \mathrm{t}$ & 2 & 0 & 0 & 0 \\
\hline Ethylene $\left(0.051\right.$ month $\left.^{-1} \mathrm{t}^{-1}\right)$ & 0.5 & 0 & 0 & 0 \\
\hline Heating degrees & 10 & 0 & 0 & 0 \\
\hline Concentration dry matter (\%) & 19 & 18 & 19 & 24 \\
\hline
\end{tabular}

- Chemical crop protection treatment number is highest in seed production even though its season is relatively short (110 days with 9.5 sprayings versus 190 days with 17 sprayings in starch production), but growers use tank mixes of fungicides, insecticides and mineral oil to keep crops healthy.

- Only organic growers burn the foliage prior to harvest.

Table 5 and Fig. 1 show emissions in $\mathrm{CO}_{2}$ equivalents to produce $1 \mathrm{t}$ of potato in each of the four systems ranging from $77 \mathrm{~kg} \mathrm{t}^{-1}$ for table potatoes to $116 \mathrm{~kg} \mathrm{t}^{-1}$ for seed potatoes. Fertilizer production costs of course are zero in organic production and almost $40 \mathrm{~kg} \mathrm{t}^{-1}$ in seed production and only $12 \mathrm{~kg} \mathrm{t}^{-1}$ in starch production due to the high amount of pig slurry.

Fertilizer and/or manure and green manure-induced field emission of $\mathrm{N}_{2} \mathrm{O}$ range from $18 \mathrm{~kg} \mathrm{t}^{-1}$ in seed to $32 \mathrm{~kg} \mathrm{t}^{-1}$ in starch production and are responsible for a substantial part of all $\mathrm{CO}_{2}$ costs for all systems, but least so in seed production where it is responsible for $16 \%$ of $\mathrm{CO}_{2}$ emission equivalents whereas in the other systems it is

Table 5 Total and relative $\mathrm{CO}_{2}$ costs of producing $1 \mathrm{t}$ of potato in the four systems

\begin{tabular}{|c|c|c|c|c|c|c|c|c|}
\hline \multirow[t]{2}{*}{ Factor } & \multicolumn{2}{|l|}{ Table } & \multicolumn{2}{|c|}{ Organic } & \multicolumn{2}{|l|}{ Seed } & \multicolumn{2}{|l|}{ Starch } \\
\hline & $\mathrm{kg}$ & Percent & $\mathrm{kg}$ & Percent & $\mathrm{kg}$ & Percent & $\mathrm{kg}$ & Percent \\
\hline Seed & 3.9 & 5.1 & 6.5 & 7.9 & 14.8 & 12.8 & 3.4 & 4.9 \\
\hline Fertilizer & 24.6 & 32.0 & 0 & 0 & 39.6 & 34.2 & 12.2 & 17.2 \\
\hline Emission & 25.1 & 32.6 & 26.3 & 31.7 & 18.2 & 15.7 & 31.8 & 24.9 \\
\hline Biocides & 5.1 & 6.7 & 0 & 0 & 16.2 & 14.0 & 9.8 & 13.9 \\
\hline Operations & 7.1 & 9.2 & 25.8 & 31.3 & 10.8 & 9.4 & 11.1 & 15.6 \\
\hline Irrigation & 1.1 & 1.4 & 2.0 & 2.4 & 0 & 0 & 0.4 & 0.6 \\
\hline Storage & 10.1 & 13.1 & 22.3 & 26.9 & 16.2 & 14.0 & 2.2 & 3.0 \\
\hline Sprout inhibition & 0.2 & 0.3 & 0 & 0 & 0 & 0 & 0 & 0 \\
\hline Total & 77.1 & 100 & 82.4 & 100 & 115.8 & 100 & 70.8 & 100 \\
\hline Nitrification inhibitor & 73.4 & -4.8 & & & 110.8 & -4.3 & 66.5 & -6.1 \\
\hline Best available fertilizer technology & 65.8 & -14.7 & & & 102.6 & -11.4 & 64.8 & -8.5 \\
\hline Transport manure or slurry & 79.3 & +2.8 & 102.2 & +24.0 & 117.6 & +1.5 & 87.0 & +22.9 \\
\hline $\mathrm{kg} \mathrm{CO} \mathrm{CO}_{2}$ per $\mathrm{t}$ dry matter & 405.1 & & 457.8 & & 609.5 & & 229.1 & \\
\hline
\end{tabular}




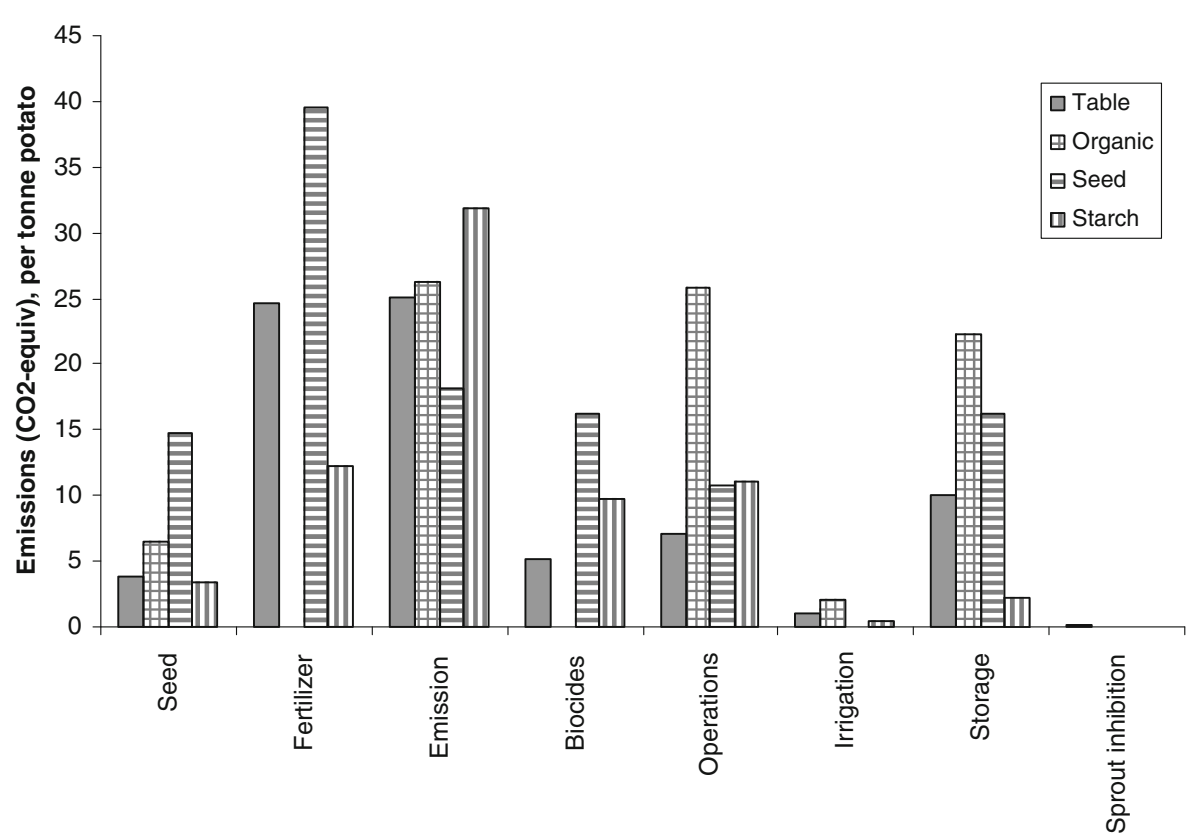

Fig. 1 Schematic representation of the various contributions of chemicals and operations to the $\mathrm{CO}_{2}$ charge of the four systems in the Netherlands

almost twice as high. The contribution of biocides, field operations and irrigation are relatively modest. Storage costs are negligible in starch production but substantial in organic production where growers cool at low temperatures with forced refrigeration to suppress sprouting as they do not apply chemical sprout suppressants.

The use of nitrification inhibitors is expected to reduce the footprint by an average of about 5\%. Switching from older to more recent (best available) fertilizers leads to an average reduction of $11.5 \%$. The CFT-Potato here assumed that the transport of pig slurry is paid by the pig farmers, so its $\mathrm{CO}_{2}$ emission is attributed to pig farming. If potato growers would have to pay as is often the case in other countries, the footprint would increase around $1.5 \mathrm{~kg} \mathrm{t}^{-1}$ for seed production and $12.5 \mathrm{~kg} \mathrm{t}^{-1}$ for starch production. Based on dry matter production only, the order of increasing $\mathrm{CO}_{2}$ cost of table-starchorganic-seed would be starch-table-organic-seed. More correct comparisons for processed potatoes, not only starch but also French fries and chips (crisps), are on dry matter basis as it largely determines the recovery rate so the footprint of the finished product. The relative contribution of chemicals (Fig. 2) clearly differs between the four systems studied. Organic production is zero at the cost of $\mathrm{CO}_{2}$ production in factories producing synthetic chemicals, and seed has the highest and table potatoes the lowest contribution from biocides of the three mainstream production methods.

\section{Concluding Remarks}

The version of the Cool Farm Tool - Potato used to calculate the $\mathrm{CO}_{2}$ charge of $1 \mathrm{t}$ of potato is not the final one-which is planned for online release in December 


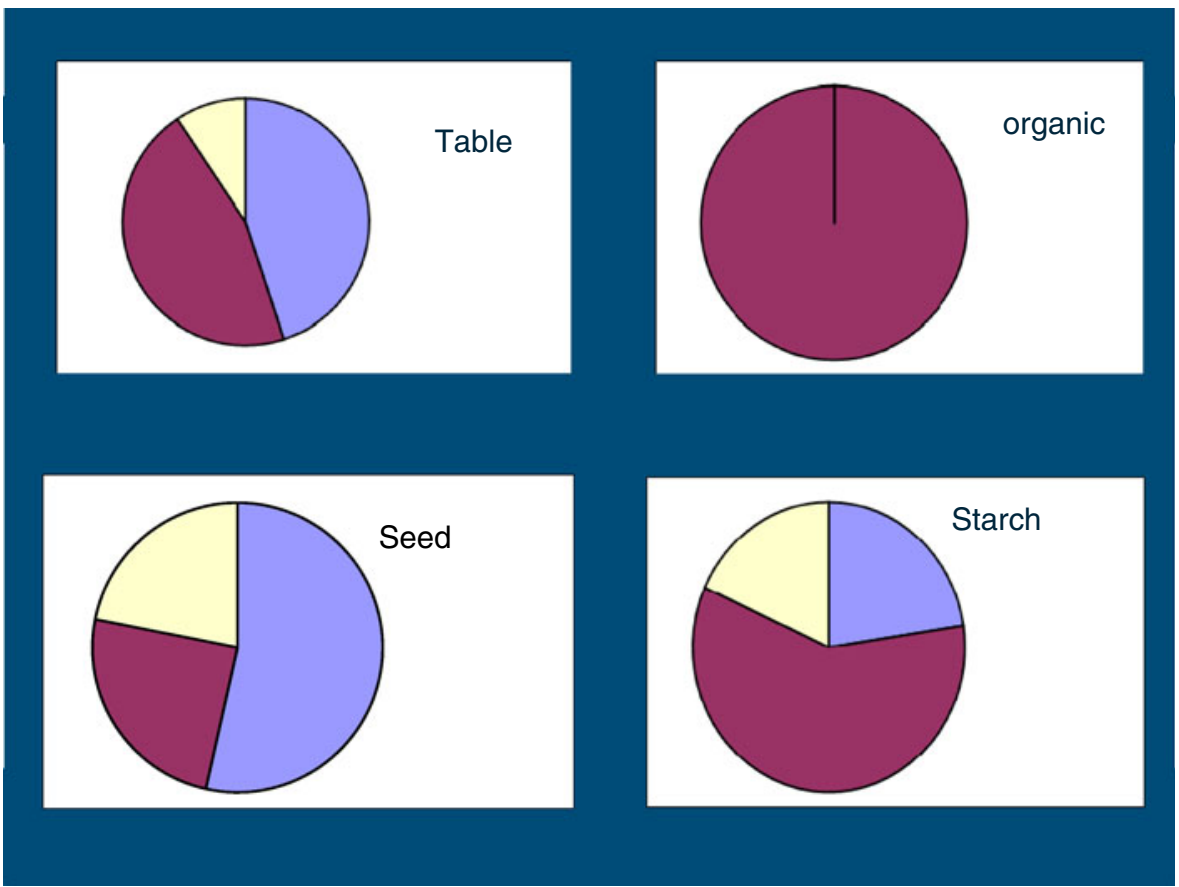

Fig. 2 Relative contributions of chemicals to the $\mathrm{CO}_{2}$ charge. Clockwise starting at 12:00 $\mathrm{h}$ fertilizer production, emission from soil and biocide production. Organic_-by nature — only has soil emissions

2011. Where a function has not yet been implemented in the tool—such as transport costs of irrigation water - it was compensated for by adding equivalent amount of water for the present study. Similarly for slurry injection, all changes made, however, will hardly influence the outcome of the calculations and certainly not the conclusions drawn from the different potato production systems in the Netherlands.

The figures obtained for potato compare reasonably well with those from Hillier et al. (2011a, b) which equate to $\sim 67 \mathrm{~kg} \mathrm{CO}_{2}$ eq $\mathrm{t}^{-1}$, using a methodology based on Lal (2004) and IPCC emissions factors for $\mathrm{N}_{2} \mathrm{O}$ in a study which did not consider seed production or primary processing and storage operations. Cross references with other crops such as wheat or oilseed rape have also been conducted and show that, although emissions on a fresh or dry matter yield basis may vary, emissions per unit energy in the harvest product vary much less (J.G. Hillier, unpublished data).

The development of the CFT-Potato has been motivated partly by a need to reflect potato specific practices and partly to encourage engagement of those associated with potato production in developing robust accounting methods. Some of the emission factors added into the CFT-Potato have been subjected to less critical review than those in the main version of the Cool Farm Tool. As more public domain information becomes available on these emission factors, it would be appropriate to update the software. Also, if in future the need is felt to add treatments hitherto not used in potato cropping (such as ethylene for sprout control which is a recent practice) or when it is calculated that harvesting costs four to five times more 
diesel than default in the CFT, then it is also appropriate to modify the tool defaults, as long as careful mention of such actions is made.

For pig slurry the emission of $\mathrm{CO}_{2}$ equivalents is incorporated and also transport costs from pig grower to the potato field and injection. This is to cover the $\mathrm{CO}_{2}$ costs of the alternative: methane production. Although it may be argued that a potato grower is simply making use of a waste product, the other side of the argument is that if it is being used as a fertilizer, then the "production" emissions from the livestock system should also be attributed to it. It is unlikely that one-size-fits-all boundaries can be established for the use of animal waste as fertilizers attributable to all farming systems; we simply note the potential impact of the assumption of zero production emissions for organic fertilizers. For the present study, we attributed all to the pig supply chain as it covers all costs that potato growers might have incurred such as transport, storage and application to the potato field.

Finally, the CFT-Potato developed here is illustrated by benchmarking four potato production systems in the Netherlands. It can also be applied by comparing raw material for processing companies and see how different systems in different countries perform. Potato production applying nitrogen through the pivot on a sandy soil in a desert area with $350 \mathrm{~kg}$ of nitrogen per ha and $900 \mathrm{~mm}$ of water may cost twice as much $\mathrm{CO}_{2}$ as rain fed potatoes in Ireland. The main aim of the tool, however, is to allow growers to gain insight in the main sources of $\mathrm{CO}_{2}$ attributions when they produce $1 \mathrm{t}$ of potatoes and means of mitigating it. They may explore this by using the tool and altering fertilizer sources and quantities and operations such as tillage and storage. The CFT-Potato does not represent a complete life cycle analysis. It does for example not include the $\mathrm{CO}_{2}$ charge of the manufacturing of the machines. There is potential to include the accounting method inside other decision support systems which would allow growers to not only explore the effect changes have on $\mathrm{CO}_{2}$ charge but also the financial implications.

Acknowledgements This research was partly funded by Pepsico-Fritolay and McCain Foods.

Open Access This article is distributed under the terms of the Creative Commons Attribution Noncommercial License which permits any noncommercial use, distribution, and reproduction in any medium, provided the original author(s) and source are credited.

\section{References}

Akiyama H, Xiaoyuan Y, Yagi Y (2010) Evaluation of effectiveness of enhanced-efficiency fertilizers as mitigation options for $\mathrm{N}_{2} \mathrm{O}$ and $\mathrm{NO}$ emissions from agricultural soils: meta-analysis. Glob Chang Biol 16:1837-1846. doi:10.1111/j.1365-2486.2009.02031.x

ASABE (2006a) Agricultural machinery management data. American Society of Agricultural and Biological Engineers Standard ASAE EP496.3. ASABE, St. Joseph, pp. 385-390

ASABE (2006b) Agricultural machinery management data. American Society of Agricultural and Biological Engineers Standard ASAE EP496.3. ASABE, St. Joseph, pp. 391-398

Bouwman AF, Boumans LJM, Batjes NH (2002) Modeling global annual $\mathrm{N}_{2} \mathrm{O}$ and $\mathrm{NO}$ emissions from fertilized fields. Global Biogeochem Cycles 16(4):1080

Brentrup F, Palliere C (2008). GHG emissions and energy efficiency in European nitrogen fertiliser production and use. Proceedings No: 639. The International Fertiliser Society, York

Ecoinvent Centre (2007) Ecoinvent data v2.0. Ecoinvent reports No.1-25, Swiss Centre for Life Cycle Inventories, Dübendorf, 2007. www.ecoinvent.org. Accessed 11 July 2011 
FAO/IFA (2001) Global estimates of $\mathrm{NH}_{3}, \mathrm{NO}$ and $\mathrm{N}_{2} \mathrm{O}$ for agricultural lands. FAO Rome ISBN 92-5104689-1, $106 \mathrm{pp}$

GHG protocol (2003) Emissions factors from cross-sector tools. http:/www.ghgprotocol.org/calculationtools/all-tools. Accessed 11 July 2011

Hillier JG, Hawes C, Squire G, Hilton A, Wale S, Smith P (2009) The carbon footprints of food crop production. Int J Agric Sust 7:107-118

Hillier J, Hilton A, Wale S, Hawes C, Squire G, Smith P (2011a) SAC newsletter carbon footprinting of crop production. www.scri.ac.uk/scri/file/PiP/Carbonfootprintingofcropproduction.pdf. Accessed 11 July 2011

Hillier J, Walter C, Malin D, Garcia-Suarez T, Mila-i-Canals L, Smith P (2011b) A farm-focused calculator for emissions from crop and livestock production. Environ Model Software 26:1070-1078

IPCC (2006) IPCC 2006 Revised Good Practice Guidelines for Greenhouse Gas Inventories. Intergovernmental Panel on Climate Change (IPCC), Institute for Global Environmental Strategies, Tokyo. http://www.ipcc-nggip.iges.or.jp/public/2006gl/vol4.html. Accessed 11 July 2011

Lal R (2004) Carbon emissions from farm operations. Environ Int 30:981-990

NMI (2011) Stikstofinhoud Groenbemesters (In Dutch, Nitrogen content of green manures) http://www. blgg.nl/sites/nmi/nl/nmi.nsf/dx/WaaierGroenbemesters.PDF/\$file/WaaierGroenbemesters.PDF. Accessed 11 July 2011

Oenema O, Wrage N, Velthof GL, van Groenigen JW, Dolfing J, Kuikman PJ (2005) Trends in global nitrous oxide emissions from animal production systems. Nutr Cycl Agroecosys 72(1):51-65

Ogle SM, Breidt FJ, Paustian K (2005) Agricultural management impacts on soil organic carbon storage under moist and dry climatic conditions of temperature and tropical regions. Biogeochemistry 72:87-121

Smith P, Powlson DS, Glendining MJ, Smith JU (1997) Potential for carbon sequestration in European soils: preliminary estimates for five scenarios using results from long-term experiments. Global Change Biol 3:67-79 